\title{
HLA antigens in multiple sclerosis of Northern Spanish population
}

\author{
C López-Larrea, D F Uría, Eliecer Coto
}

\begin{abstract}
HLA-A, -B, -C, -DR, -DQ antigens were studied in 43 multiple sclerosis (MS) patients with clinically definite remittent sclerosis from Asturias (North Spain). The prevalence of HLA-B7, B7 and $B 27$ were significantly increased in MS. HLA-B35 was under-represented in these patients. DR2 was increased but not significantly. No association with DQw1 was discovered. The existence of several susceptibility factors in the more common B7/DR2/DQw1 haplotype is discussed.
\end{abstract}

Several studies have found an association between susceptibility to multiple sclerosis (MS) and HLA-A3,-B7 antigens. ${ }^{1}$ This association seems to be secondary to a stronger DR2 and DQw1 in different white populations. ${ }^{2}$ The strength of A3-B7-DR2-DQw1 associations decreases from Northern to Southern Europe and correlates with the known MS latitude prevalence distribution. ${ }^{3}$ However, a few controversial studies from Mediterranean populations have been reported. ${ }^{45}$

The objective of this work has been to map susceptibility genes within the HLA in a sample of Northern Spanish MS patients. Furthermore, a correlation has been made with the different haplotypic A3-B7-DR2DQwl associations which appear in Spanish and other North European populations.

\section{Patients and methods \\ Population sample}

HLA class I and class II antigens were studied in 43 unrelated patients from Northern Spain (Asturias region) with clinically definite remittent MS. This area has medium frequency of MS (prevalence of 20/100 000) The diagnostic criteria used was established by Poser et $a l .^{6}$ Healthy volunteers from a sample of the Spanish population (100) were used for the HLA control.

\section{HLA typing}

HLA-A, -B, -C, -DR typing was performed on defibrinated blood as previously described. ${ }^{7}$ Local and Ninth HLA Workshop antisera were used.

\section{Statistical analysis}

Analysis was carried out using a computer programme. When the frequency antigens deviated significantly from those of normal individuals, the corresponding $p$ values were multiplied by the number of antigens which were considered only in a series with more than 20 alleles. The chi-square test with Yates's correction was used to compare the frequencies of HLA antigens. Relative risk (RR) was calculated according to Svejgaard et al. ${ }^{8}$

\section{Results}

The HLA antigen frequencies of 43 patients with MS and the HLA control are listed in the table. Significant association was found with B7 $(\mathrm{p}<0.01)$ and B27 $(\mathrm{p}<0.05)$. B35 was significantly under-represented in the patients $(p$ $<0.01)$. DR5 was also decreased in MS $(5.7 \%$ versus $20 \cdot 7 ; \mathrm{p}<0.05$ ).

HLA-DR2 was increased but not significantly $(37.7 \%$ versus 23.9$)$ as expected by the results found in other ethnic groups. The HLA-DR2 increment was probably secondary to the observed B7-DR2 association. However, the frequency of DR2 in the Northern Spanish region was comparable to that reported in other white populations (not shown). The association B7-DR2 was also increased in MS $(27.9 \%$ versus $6.1 \% ; \mathrm{p}<0.01$ ) but the B7-DR2 risk did not differ significantly from the B7 relative risk (4.2 versus $3 \cdot 4)$. DQw1 was not found associated with MS as might have been expected because of the well established linkage disequilibrium DR2/ DQwl.

\section{Discussion}

Several studies have shown an association between susceptibility to MS disease and the HLA antigens. HLA-DR2 has been described as a related antigen in different ethnic groups. ${ }^{5}$ The common A3/B7/DR2 haplotype was found to be increased in Northern Europeans. ${ }^{1}$ It is clear that DR2 itself does not cause susceptibility in MS. In this context, DQw1 showed a strong association as expected because of the well established linkage DQw1-DR2. ${ }^{2}$ Genomic HLA-class II typing with DQalpha and DRbeta cDNA probes has confirmed these results. ${ }^{9}$ In

Table HLA antigen frequencies ( $\%$ ) in Northern Spanish patients with multiple sclerosis and normal controls

\begin{tabular}{|c|c|c|c|c|}
\hline Antigen & $\begin{array}{l}M S \text { patients } \\
(n=43)\end{array}$ & $\begin{array}{l}\text { Controls } \\
(n=100)\end{array}$ & $\begin{array}{l}\text { Relative } \\
\text { risk }\end{array}$ & $\chi^{2}$ \\
\hline 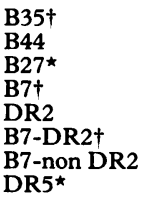 & $\begin{array}{r}7 \cdot 5 \\
25 \cdot 0 \\
2 \cdot 2 \\
34 \cdot 0 \\
37 \cdot 7 \\
27 \cdot 9 \\
7 \cdot 0 \\
5 \cdot 7\end{array}$ & $\begin{array}{r}27 \cdot 2 \\
11 \cdot 3 \\
9 \cdot 4 \\
13 \cdot 0 \\
23 \cdot 9 \\
6 \cdot 1 \\
6 \cdot 9 \\
20 \cdot 7\end{array}$ & $\begin{array}{l}0 \cdot 22 \\
0 \cdot 38 \\
4 \cdot 68 \\
3 \cdot 42 \\
1.92 \\
4 \cdot 20 \\
0 \cdot 84 \\
0 \cdot 23\end{array}$ & $\begin{array}{l}8 \cdot 1 \\
3 \cdot 9 \\
3 \cdot 8 \\
8.9 \\
3 \cdot 1 \\
8 \cdot 0 \\
0 \cdot 1 \\
5 \cdot 8\end{array}$ \\
\hline
\end{tabular}

${ }^{\star} p<0.05 ; \mathrm{pp}<0.01$. 
contrast these HLA associations were not evident in Orientals. ${ }^{10}$ There has been controversy over the relationship of ethnic groups of Mediterranean origin. ${ }^{1-3}$ Populations in South Europe have not been sufficiently investigated. Our results suggest that B7 is closely associated to the disease in Northern Spanish MS patients. DR2 and DQw1 are not significantly increased and play a secondary role as susceptibility factors. The negative association of B35 and DR5 is thought to have a protective role against the development of the disease. It was observed that the more frequent B7/DR2 haplotype in white populations is weakly maintained in the Spanish population. ${ }^{7}$ The strength of the B7/DR2 haplotype decreases from Northern to Southern Europe and it is independent of the similar frequency of B7 and DR2 found in Spanish and other reported Northern European populations. ${ }^{137}$ This correlates with the difference in prevalence of MS at different MS latitudes. ${ }^{3}$ It supports the idea that B7 and DR2 could act as independent genetic factors of susceptibility. It is likely that a dysequilibrium between HLAclass I and HLA-class II play a role in the pathogenesis of MS. These findings are consistent as several closely linked MS susceptibility factors may exist within the A3/B7/DR2/DQw1 haplotype. The presence of some of these genetic factors could be necessary for the development of MS in different populations.

1 Compston A. Genetic factors in the aetiology of multiple sclerosis. In: McDonald MI, Silberberg, eds. Multiple sclerosis. In: McDonald MI, Silberberg, eds.
sclerosis. London: Butterworths, 1986:56-73.

2 Francis DA, Batchelor JR, McDonald WI, et al. Multiple sclerosis in North East Scotland. An association with sclerosis in North East Scotland. A
HLA-DQw1. Brain 1987;110:181-96.

3 Kurtze JF. Geographic distribution of multiple sclerosis: an update with special reference to Europe and the Mediterranean region. Acta Neurol Scand 1980;62:65-80.

4 Georgaras A, Constantopoulos C, Lycidacis C, Zervas J. HLA antigens and multiple sclerosis in Greeks. $J$ Neurol Neurosurg Psychiatry 1984;47:751-2.

5 Batchelor JR, Compston DA, McDonald WII. HLA and multiple sclerosis. In: The HLA system. Br Med Bull 1978;34:279-84

6 Poser CM, Paty DW, Scheinberg L, et al. New diagnostic criteria for multiple sclerosis: guidelines for research protocols. Ann Neurology 1983;13:227-31.

7 Arnaiz-Villena A, Rodriguez de Córdoba S, Vela F, Pascual JC, Cervero J, Bootello A. HLA antigens in a sample of the Spanish population: common features among Spaniards, Basques and Sardinians. Hum Genet 1981;58:344-8.

8 Svejgaard A, Jersild C, Staub-Nielsen L, Bodmer WF. HLA antigens and disease. Statistical and genetic considerations. Tissue Antigens 1974;4:95-9.

9 Marcadet A, Massart C, Semana G, Fauchet R, Sabourau O Merienne M, Dausset J, Cohen D. Association of class II HLA-DQ chain DNA restriction fragments with multiple sclerosis. Immunogenetics 1985;22:93-6.

10 Hawkins BR, Yu YL, Woo E, Huang CY. No apparent association between HLA and multiple sclerosis in south ern Chinese. J Neurol Neurosurg Psychiatry 1988;51: 